\title{
Permeable pavements - green infrastructures as a flood mitigation measure
}

\author{
M.L. Afonso ${ }^{a}$, M. Dinis-Almeida and C.S. Fael \\ Centre of Materials and Building Technologies, University of Beira Interior, Covilhã, Portugal.
}

\begin{abstract}
Permeable asphalt pavements have been one of the solutions used to increase the permeability of road pavements given the growing urbanization and climate change. The high porosity and permeability of surface layers with PA (porous asphalt) mixtures allows the water infiltration and, consequently, reduces superficial runoff and contributes to the recharge of underground aquifers. However, the infiltration capacity may be impaired by clogged pores with sediments. The double layer porous asphalt (DLPA) was developed to mitigate this effect. This is a key issue in the pavements' service life. Information on the clogging processes in these layers is not yet well characterized. The study was carried out using a rainfall simulator in order to generate design storm events with a known intensity and duration. The experimental methodology adopted took into account different phases of evaluation of the infiltration capacity with two clogging cycles (500 and $1000 \mathrm{~g} \mathrm{~m}^{-2}$ ). The DLPA infiltration capacity was evaluated in the different phases after different precipitation events $\left(100,200\right.$ and $\left.300 \mathrm{~mm} \mathrm{~h}^{-1}\right)$. The results showed that, in general, the double layer porous asphalt has the capacity to drain the water, even after clogging and with lower voids content. The infiltration capacity was partially restored when subjected to simple maintenance.
\end{abstract}

Keywords: porous, asphalt, water, infiltration, clogging, maintenance

\section{INTRODUCTION}

Increasing urbanization associated with lack of management and inappropriate land use decreases the natural storage capacity for rains, modifying the drainage patterns. In this context, climate change has led to higher and more frequent peak flows, causing an instantaneous increase in storm water (Christensen and Christensen, 2003; Willems et al., 2012). Urban storm water has been recognized as one of the major sources of pollution in the world (Siriwardene et al., 2007). When in contact with urban drainage areas it allows the displacement of pollutants to underground soils, for example, harming the land for agriculture. Permeable pavement systems, integrated in sustainable drainage systems (SUDs), are being used as techniques to reduce the impacts of urbanization associated with floods, promoting the control of the volume of rainwater. The main advantages associated with the application of permeable pavements are the control of rainwater runoff, the restoration of groundwater and the improvement of water quality for the soil.

The use of permeable pavements as urban intervention has been proposed as a green infrastructure (GI) solution to mitigate the effects of climate change in recent years around the world (EPA, 2014). GI aims at the conservation of nature, combined with the use of land related to agriculture, forestry, leisure and recreation, and adaptation to climate change. Concretely, the porous asphalt mixtures used in permeable asphalt pavement (PAP) have unique characteristics that allow them to infiltrate the rainwater through its porous structure. The typical void content of the porous asphalt is $16-25 \%$ compared to $4-6 \%$ of the void content of a conventional hot mix asphalt (Asphalt Institute, 2003; Putman and Kline, 2012). Waters may either infiltrate directly into the underlying soils or be stored in a storage reservoir below them (Yong et al., 2008).

${ }^{\mathrm{a}}$ E-mail: marcia.afonso@ubi.pt 
The challenge posed in these pavement systems is to maintain infiltration capacity over the years of service due to lack of maintenance practices, with the greatest concern being susceptibility to clogging (James and Von Langsdorff, 2003). Clogging may be the result of accumulation of fine sand and sediment in the void spaces of the porous asphalt. The smaller particles fill the spaces between the larger particles, so the thinner those particles are, the greater the clogging rate (Pratt et al., 1995). A narrower particle size distribution of the aggregates on the surface of the porous asphalt allows retention of the sediments and limits their entry into the underlying layers. This is the effect of the application of a double layer porous asphalt (DLPA) (Hamzah et al., 2013). Immediately below the surface layer with thinner-sized aggregates a layer with thicker aggregates is applied, which allows the infiltration of the water to the layers with open graded aggregates with a lower sediment influence, as these are retained in the surface layer.

Some studies previously performed have evaluated the state of clogging of permeable asphalt pavements in the laboratory (Fwa et al., 1999; Yong et al., 2013) and in situ (Kayhanian et al., 2012). In the study by Yong et al. (2013) in permeable pavement systems, the application of rainfall with variable flow magnitudes and with drying periods, doubled the useful life, suggesting that the climatic conditions influence the drainage of the pavements. The case study carried out by Kayhanian et al. (2012) in car parks with porous asphalt mixtures showed that specimens collected from the field had lower porosity in the first $25 \mathrm{~mm}$. Analysing images of core specimens using X-ray, found that most cases of clogging occurred on the surface of the pavement.

Permeable pavements should be inspected several times during the first months after construction and thereafter at least once a year (Shirke and Shuler, 2009). Existing surface sediments over time can be corrected by maintenance to limit the risks of clogging and pollution (Legret et al., 1996). The most commonly used maintenance techniques in the process of cleaning permeable pavements are sweep, vacuum and high pressure jet washing (Baladès et al., 1995; Sansalone et al., 2012; WAPA, 2015).

A permeable asphalt pavement, as a multifunctional green infrastructure, can promote the restoration of the hydrological cycle, improve safety in hydroplaning, reduce tire noise on the pavement and improve urban road drainage (Chu et al., 2017; Fwa et al., 2015; Legret et al., 1999; Sansalone et al., 2012). However, infiltration and clogging are two aspects of interest, in a continuous process of discussion. This investigation evaluates the infiltration capacity of a double layer porous asphalt before and after two cycles of clogging with graded fine sand, at different precipitation intensities.

\section{MATERIALS AND METHODS}

\section{Double layer porous asphalt (DLPA)}

The DLPA evaluated in this study consists of two asphalt mixtures with draining characteristics that give them a high porosity. This solution improves the function and durability of porous mixtures and reduces the problem of clogging in permeable asphalt pavements. The porous asphalt with fine aggregates of up to $10 \mathrm{~mm}$ at the surface (PA1) functions as a sieve, which limits the entry of sediments into the lower mix with coarse aggregates of up to $15 \mathrm{~mm}$ (PA2). The composition of the porous asphalt considered is presented in Afonso et al. (2017) which evaluates the addition of cellulosic fibers. The content of the polymer modified bitumen was 5.2 and 5.1\% for PA1 and PA2, respectively. The $0.30 \times 0.30 \mathrm{~m}$ pavement slabs were produced in the laboratory with $3 \mathrm{~cm}$ thickness for PA1 and $4 \mathrm{~cm}$ for PA2. The PA1 slab obtained a porosity of $17.2 \%$ and the PA2 slab $22.6 \%$.

\section{Clogging material}

In simulations of the effect of clogging performed in the laboratory, the most common material used is sand with a known size distribution curve (Sansalone et al., 2012; Shirke and Shuler, 2009; Tan et al., 2003). The sand used as clogging material in this study is of mostly granite origin. In the clogging process, the larger particles of sand accumulate in the permeable floor and the spaces between them are filled with dust or fine particles, 
generated from the contact between the vehicle tires and the pavement surface, which decrease the permeability and clog the pores, making the pavement impermeable (Kayhanian et al., 2012). The fine sand used was physically characterized by sieve analysis, obtaining a D50 of $0.44 \mathrm{~mm}$, guaranteeing an accentuated graduation in fine particles.

\section{Rain simulator}

The test was performed with the help of a rain simulator developed for this purpose. The rain simulator, with a sprinkler nozzle, was adjusted to obtain the desired precipitation intensity characteristics. It was fed by a pump from a 1000-L tank, controlled by a pressure gauge. The slabs were tested on a laboratory-built support with dimensions of $0.50 \mathrm{~m}$ in height and $0.30 \mathrm{~m}$ in width and length. The height from the surface of the DLPA to the sprinkler was $2.60 \mathrm{~m}$.

Calibration of the precipitation intensities of 100,200 and $300 \mathrm{~mm} \mathrm{~h}^{-1}$ was achieved with the flow measurement method. For this, the time required to collect a certain volume of water in the study area with different pressures was recorded. The selected pressure was 2.6 bar. To operate each of the desired intensities without changing the pressure, the test stand was positioned at strategically located points, properly tested, in the center line of the sprinkler nozzle. As for the uniformity of precipitation distribution, the Christiansen's uniformity coefficient (CUC) was calculated for each precipitation intensity. The values of 78.84, 72.24 and $68.51 \%$ were obtained for the intensities of 100,200 and $300 \mathrm{~mm} \mathrm{~h}^{-1}$, respectively. According to Merriam and Keller (Merriam and Keller, 1978) the CUC value should be above $70 \%$. Although one of the results was lower, it was considered adequate given its proximity.

\section{Evaluation methodology for the infiltration capacity}

The test methodology consisted of four phases of evaluation of infiltration capacity for intensities of 100, 200 and $300 \mathrm{~mm} \mathrm{~h}^{-1}$ for periods of $50 \mathrm{~min}$. The support structure of the DLPA has the possibility of collecting the runoff and infiltrated water. The first phase corresponded to the initial evaluation of the DLPA, that is, after construction with no clogging for each precipitation intensity. In the second phase, the first clogging cycle was applied with a quantity of $500 \mathrm{~g} \mathrm{~m}^{-2}$ of clogging material ( $45 \mathrm{~g}$ ), dispersed manually on the PA1 surface. After this application, the infiltration test was performed for each precipitation intensity. In the third phase, the second stage process is repeated, applying the second clogging cycle of 500 to $1000 \mathrm{~g} \mathrm{~m}^{-2}$ of total clogging material. Finally, the fourth phase concerns simple maintenance with sweep and vacuum, according to the technique most used in road cleaning, followed by the infiltration test. The slabs were weighed for mass comparison, before and after each of the test phases.

\section{RESULTS AND DISCUSSION}

The results analysis focuses on the infiltration capacity of the DLPA and the mass of each of the layers that compose it.

The infiltration capacity of the DLPA, initial and after clogging is presented in Figure 1, for the three precipitation intensities studied. In the course of the practical tests it was found that no runoff occurred, that flow resulted in water infiltrating the two layers.

The period of time for the gradual increase of infiltration, for all intensities and for the two evaluation phases presented, corresponds to the wetting time of the porous asphalt. That is, even with the pre-wetting of the DLPA, the time elapsed until the start of the test was sufficient for the mixtures to drain most of the water from the pre-wetting, keeping only the wet appearance at the start of the tests. This leads to the behavior presented by the DLPA, where in all the tests carried out, as time elapsed, the layers infiltrated all the water and no surface flow occurred, maintaining a constant infiltration until the end of the test. Thus, either after construction or after clogging, the DLPA has full infiltration capacity. 


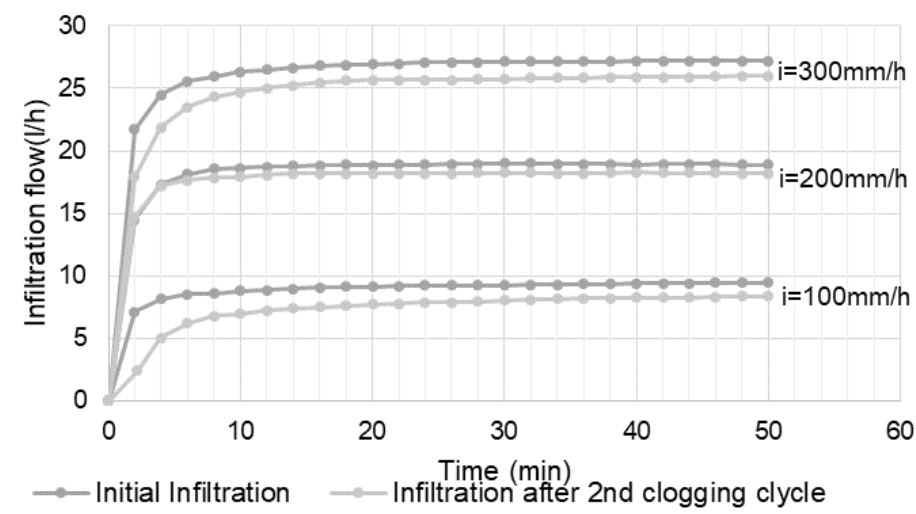

Figure 1. Initial infiltration capacity and after clogging for rainfall intensities of 100, 200 and $300 \mathrm{~mm} \mathrm{~h}^{-1}$.

By analysing the results together, for all intensities, it is verified that after the application of $1000 \mathrm{~g} \mathrm{~m}^{-2}$ of clogging material, the infiltration capacity of the DLPA decreases slightly, presenting a deviation from the initial infiltration without clogging. However, this deviation is not high, presenting differences of about $12 \%$ at the 50 -min test for the precipitation intensity of $100 \mathrm{~mm} \mathrm{~h}^{-1}$ and $5 \%$ for the precipitation intensities of 200 and 300 $\mathrm{mm} \mathrm{h}^{-1}$.

Figure 2 shows the infiltration capacity during the four phases of testing for the precipitation intensity of $300 \mathrm{~mm} \mathrm{~h}^{-1}$. The vertical axis presents the most representative range of values, for which the results had greater significance.

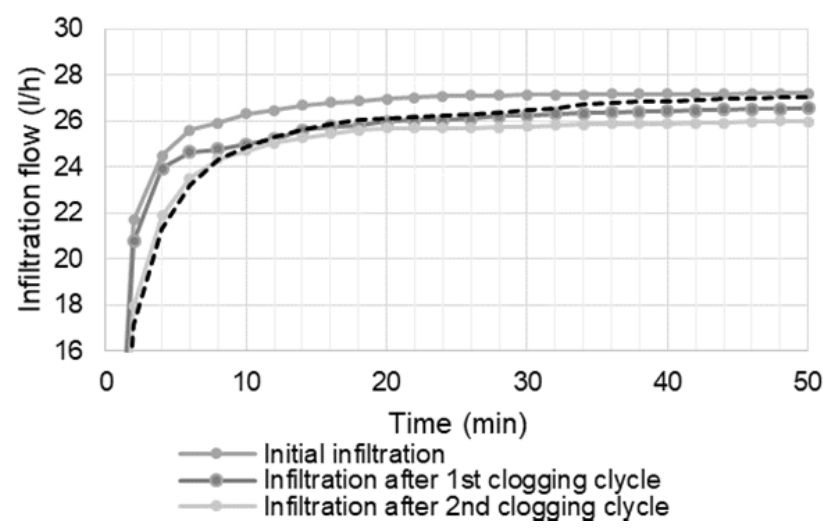

Figure 2. Infiltration capacity during the four evaluation phases for the rainfall intensity of $300 \mathrm{~mm} \mathrm{~h}^{-1}$.

The graph shows that in the initial test period corresponding to the first clogging cycle the behavior of the infiltration capacity coincides with the same period in the test without clogging. Thus, after application of the clogging material the DLPA behaves exactly as after construction in the first few minutes of testing. After about $4 \mathrm{~min}$ the behavior deviates due to the effect of the filling material which decreases infiltration, distancing itself from the initial behavior and remaining constant until the end of the test.

In the second clogging cycle, there is a decrease in the infiltration capacity, relative to the $1^{\text {st }}$ cycle, clearly due to the doubling of the amount of clogging material applied, which creates a delay in the passage of water through the pores.

It is verified, once again, an overlap in the values of the infiltration capacity in the initial period after the second clogging cycle and after maintenance. In this case, the DLPA 
exhibits this behavior because at the beginning of the test after maintenance there was still influence of the clogging material that could not be removed with the cleaning. However, after about 12 min of testing, the DLPA recovers the infiltration capacity above the $1^{\text {st }}$ and $2^{\text {nd }}$ clogging cycles and is close enough to the initial infiltration capacity. The results allow to conclude that DLPA recovers the infiltration capacity after simple maintenance.

The mass variation in each slab (PA1 and PA2) was analyzed between the initial masses and after each evaluation phase under wet and dry conditions. The percentage differences obtained are shown in Table 1.

Table 1. Percentage by mass of the two slabs that compose DLPA.

\begin{tabular}{lcc}
\hline & $\begin{array}{c}\text { PA1 slab } \\
\% \text { by mass }\end{array}$ & $\begin{array}{c}\text { PA2 slab } \\
\% \text { by mass }\end{array}$ \\
\hline Wet conditions & & \\
Initial and after 1 ${ }^{\text {st }}$ clogging cycle & 0.92 & 0.31 \\
Initial and after 2nd clogging cycle & 1.79 & 0.40 \\
Initial and after maintenance followed by infiltration & 0.59 & 0.01 \\
\hline Dry conditions & & \\
Initial and after maintenance & 0.83 & 0.07 \\
Initial and after maintenance followed by infiltration & 0.67 & 0.02 \\
\hline
\end{tabular}

By analysis of the results in the surface layer (PA1 slab), in wet conditions, an increase of mass in the two clogging cycles is confirmed, due to the application of the clogging material. In the lower layer (PA2 slab) the differences decreased due to the limitation of the sediment passage through the surface layer clogged in the $1^{\text {st }}$ cycle. The reduction of mass in the PA1 slab between the beginning and after the maintenance phase results from the cleaning performed on the surface of it. Regarding PA2, its loss was due to the washing of fine material in the pores. However, analysis in wet conditions does not allow accurate assessment of the amount of clogging material in both of the slabs, given the possible existence of water entrapped in it, which is difficult to measure.

In dry conditions, DLPA shows excellent results after simple maintenance, with a residual increase of mass of less than $1 \%$. The small difference between the initial mass and after maintenance with infiltration may be due to the finer materials that were housed in the two layers and were washed by the water infiltrated during the tests with the different intensities. It can be observed, by observation of the results, that the material housed in the second layer is non-existent as it presents differences of less than $0.1 \%$. By visual observation of the two slabs, it was verified that PA1 had a higher amount of thin sediments at the surface, compared to PA2, where the visualization of these sediments is imperceptible. These facts lead to the results of the infiltration capacity evaluation after simple maintenance (Figure 2), where the infiltration of the DLPA approached the initial one. It is concluded that simple maintenance (sweeping and vacuuming) on a pavement with DLPA is effective in recovering its main function, fully infiltrating rainwater.

\section{CONCLUSIONS}

The study concluded that the clogging state affects the behavior of the DLPA as to its capacity to infiltrate rainwater. At any stage of evaluation, the DLPA performance showed identical infiltration capacity results for the studied precipitation intensities. The infiltration capacity after the clogging cycles decreased slightly relative to the initial state of the DLPA. This was due to the clogging of the pores of the PA1 slab on the surface.

In summary, this study allows to prove the advantage of the use of a double layer porous asphalt, since this allows the infiltration of the waters, even in clogged conditions. Under these conditions, a simple maintenance allows the set of porous asphalt to recover their infiltration capacity. Research suggests that even using common maintenance techniques it is possible to obtain good results and maintain the functionality of the pavement. 


\section{ACKNOWLEDGEMENTS}

This work is supported with Portuguese national funds by FCT - Foundation for Science and Technology within the UID/ECI/04082/2013 project.

\section{Literature cited}

Afonso, M.L., Dinis-Almeida, M., and Fael, C.S. (2017). Study of the porous asphalt performance with cellulosic fibres. Constr. Build. Mater. 135, 104-111 https://doi.org/10.1016/j.conbuildmat.2016.12.222.

Asphalt Institute. (2003). Mix Design Methods for Asphalt Concrete and Other Hot Mix Types (Lexington, KY, USA: Asphalt Institute), pp.141.

Baladès, J.-D., Legret, M., and Madiec, H. (1995). Permeable pavements: pollution management tools. Water Sci. Technol. 32 (1), 49-56 https://doi.org/10.2166/wst.1995.0012.

Christensen, J.H., and Christensen, O.B. (2003). Severe summertime flooding in Europe. Nature 421 (6925), 805806 https://doi.org/10.1038/421805a. PubMed

Chu, L., Fwa, T.F., and Tan, K.H. (2017). Evaluation of wearing course mix designs on sound absorption improvement of porous asphalt pavement. Constr. Build. Mater. 141, 402-409 https://doi.org/10.1016/j. conbuildmat.2017.03.027.

EPA. (2014). Using Green Infrastructure to Mitigate Flooding in La Crosse, WI. https://www.epa.gov/ sites/production/files/2015-10/documents/lacrosse_tech_assistance.pdf.

Fwa, T., Tan, S., and Guwe, Y. (1999). Laboratory evaluation of clogging potential of porous asphalt mixtures. Transp. Res. Rec. 1681, 43-49 https://doi.org/10.3141/1681-06.

Fwa, T.F., Lim, E., and Tan, K.H. (2015). Comparison of permeability and clogging characteristics of porous asphalt and pervious concrete pavement materials. Transp. Res. Rec. 2511 (1), 72-80 https://doi.org/10.3141/2511-09.

Hamzah, M.O., Abdullah, N.H., Voskuilen, J.L.M., and van Bochove, G. (2013). Laboratory simulation of the clogging behaviour of single-layer and two-layer porous asphalt. Road Mater. Pavement Des. 14 (1), 107-125 https://doi.org/10.1080/14680629.2012.749803.

James, W., and Von Langsdorff, H. (2003). The use of permeable concrete block pavement in controlling environmental stressors in urban areas. Paper presented at: $7^{\text {th }}$ International Conference on Concrete Block Paving (Sun City, South Africa).

Kayhanian, M., Anderson, D., Harvey, J.T., Jones, D., and Muhunthan, B. (2012). Permeability measurement and scan imaging to assess clogging of pervious concrete pavements in parking lots. J. Environ. Manage. 95 (1), $114-$ 123 https://doi.org/10.1016/j.jenvman.2011.09.021. PubMed

Legret, M., Colandini, V., and Le Marc, C. (1996). Effects of a porous pavement with reservoir structure on the quality of runoff water and soil. Sci. Total Environ. 189-190, 335-340 https://doi.org/10.1016/00489697(96)05228-X.

Legret, M., Nicollet, M., Miloda, P., Colandini, V., and Raimbault, G. (1999). Simulation of heavy metal pollution from stormwater infiltration through a porous pavement with reservoir structure. Water Sci. Technol. 39 (2), 119-125 https://doi.org/10.2166/wst.1999.0101.

Merriam, J.L., and Keller, J. (1978). Farm Irrigation System Evaluation: a Guide for Management (Logan, UT, USA: Logan State University), pp.271.

Pratt, C.J., Mantle, J.D.G., and Schofield, P.A. (1995). UK research into the performance of permeable pavement, reservoir structures in controlling stormwater discharge quantity and quality. Water Sci. Technol. 32 (1), 63-69 https://doi.org/10.2166/wst.1995.0016.

Putman, B.J., and Kline, L.C. (2012). Comparison of mix design methods for porous asphalt mixtures. J. Mater. Civ. Eng. 24 (11), 1359-1367 https://doi.org/10.1061/(ASCE)MT.1943-5533.0000529.

Sansalone, J., Kuang, X., Ying, G., and Ranieri, V. (2012). Filtration and clogging of permeable pavement loaded by urban drainage. Water Res. 46 (20), 6763-6774 https://doi.org/10.1016/j.watres.2011.10.018. PubMed

Shirke, N.A., and Shuler, S. (2009). Cleaning porous pavements using a reverse flush process. J. Transp. Eng. 135 (11), 832-838 https://doi.org/10.1061/(ASCE)0733-947X(2009)135:11(832).

Siriwardene, N.R., Deletic, A., and Fletcher, T.D. (2007). Clogging of stormwater gravel infiltration systems and filters: insights from a laboratory study. Water Res. 41 (7), 1433-1440 https://doi.org/10.1016/j.watres.2006. 12.040. PubMed

Tan, S.-A., Fwa, T.-F., and Han, C.-T. (2003). Clogging evaluation of permeable bases. J. Transp. Eng. 129 (3), 309315 https://doi.org/10.1061/(ASCE)0733-947X(2003)129:3(309). 
WAPA. (2015). Porous Asphalt Pavements, pp.12. http://www.wispave.org/wp-content/uploads/dlm_uploads/ WAPA_Tech_Bulletin_Porous_Asphalt_Pavements_2015-09.pdf.

Willems, P., Arnbjerg-Nielsen, K., Olsson, J., and Nguyen, V.T.V. (2012). Climate change impact assessment on urban rainfall extremes and urban drainage: methods and shortcomings. Atmos. Res. 103, 106-118 https://doi. org/10.1016/j.atmosres.2011.04.003.

Yong, C.F., Deletic, A., Fletcher, T.D., and Grace, M.R. (2008). The clogging behaviour and treatment efficiency of a range of porous pavements. Paper presented at: $11^{\text {th }}$ International Conference on Urban Drainage (Edinburgh, Scotland, UK).

Yong, C.F., McCarthy, D.T., and Deletic, A. (2013). Predicting physical clogging of porous and permeable pavements. J. Hydrol. (Amst.) 481, 48-55 https://doi.org/10.1016/j.jhydrol.2012.12.009. 
